\title{
Detection of Toxoplasmosis in Renal Transplant Recipients by ELISA and PCR Methods in Ahvaz, South-West of Iran
}

\author{
Shahrzad Soltani ${ }^{1}$, Shahram Khademvatan ${ }^{1,2}$, Jasem Saki ${ }^{1,3,}$, , Heshmatollah Shahbazian ${ }^{4}$ \\ ${ }_{1}^{1}$ Department of Medical Parasitology, Ahvaz Jundishapur University of Medical Sciences, Ahvaz, IR Iran \\ ${ }^{2}$ Cellular and Molecular Research Center, Ahvaz Jundishapur University of Medical Sciences, Ahvaz, IR Iran \\ ${ }^{3}$ Health Research Institute, Infectious and Tropical Diseases Research Center, Ahvaz Jundishapur University of Medical Science, Ahvaz, IR Iran \\ ${ }^{4}$ Department of Nephrology, Golestan Hospital and Diabetes Research Center, Ahvaz Jundishapur University of Medical Sciences, Ahvaz, IR Iran \\ ${ }^{*}$ Corresponding author: Jasem Saki, Department of Medical Parasitology, Ahvaz Jundishapur University of Medical Sciences, Ahvaz, IR Iran. PO Box: 613715794 . Tel: +98-6113367543-50, \\ Fax:+98-6113332036, E-mail: jasem.saki@gmail.com.
}

Received: August 7, 2012; Revised: November 12, 2012; Accepted: December 15, 2012

\begin{abstract}
Background: Toxoplasmosis is an opportunistic infection caused by Toxoplasma gondii. That is asymptomatic in the majority of patients, but it can be life threatening in immune-compromised subjects, such as patients with HIV and organ transplant recipients.

Objectives: This study aimed to determine the Toxoplasmosis in Renal Transplant Recipients in Ahvaz, South-West of Iran.

Materials and Methods: A total of 100 patients and 100 healthy subjects participated in this study. The specific IgG and IgM antibodies of T. gondii were detected in the two groups by ELISA and the presence of T. gondii in the blood samples was evaluated by GRA6 PCR.

Results: 34 (34\%) of the renal transplant recipients and 26 (26\%) of the control group were positive for anti-Toxoplasma IgG. In addition $18(18 \%)$ of the renal transplant recipients and $4(4 \%)$ of the control group were positive for anti-Toxoplasma IgM. For both values of the antibodies, differences were statistically significant $(\mathrm{P}<0.025$ and $\mathrm{P}<0.001$ respectively). The $\mathrm{PCR}$ results indicated the presence of $T$. gondii parasite in 2 blood samples of recipients, but not in those of the healthy control.

Conclusions: According to the findings of the current study, renal transplant recipients have a higher prevalence of toxoplasmosis than healthy people and also there is disseminated infection in the patients. Therefore to prevent the severe complications screening and follow up of renal transplant recipients for toxoplasmosis should not be neglected.
\end{abstract}

Keywords: Toxoplasmosis; Kidney Transplantation; Enzyme-Linked Immunosorbent Assay; Polymerase Chain Reaction

\section{Background}

Toxoplasma gondii is an obligate intracellular parasite with a worldwide distribution (1). It was first discovered by Nicolle and Manceaux in 1908 (2). This microorganism has very low host specificity and will probably infect almost any mammals and birds (3). It was reported in about $20 \%$ to $90 \%$ of the adult population in different regions of the world who had contact with this parasite (4). The prevalence of this organism depends on many factors such as age, geographical area, consumption of raw or half-cooked meat and contact with cats. In Iran, the seroprevalence of this infection has been reported between 40 and $70 \%$ at different regions (5).

This parasite is a well-known opportunistic pathogen in immunocompromised subjects, including patients with HIV and organ transplant recipients $(6,7)$. It remains a rare but important pathogen in renal transplant recipients (8-10). Renal transplant patients must take immunosuppressive drugs to prevent rejection and decrease the immune systemic response $(11,12)$. By continuous admin- istration of these drugs, they are prone to acquire many opportunistic infections such as toxoplasmosis $(13,14)$. Toxoplasmosis in immune-compromised patients may result from reactivation of past infection or transmission to the host from an infected donor $(13,15)$.

There were various clinical presentations of toxoplasmosis in renal transplant recipients. Fever (the most frequent clinical sign) (85\%), (15), Neurologic symptoms such as somnolence, confusion, altered consciousness, seizures, headache, drowsiness and lethargy were also observed $(16,17)$. However Clinical signs alone are unable to diagnose toxoplasmosis, so confirmatory parasitological and serological evaluations are needed (18). Diagnosis and follow up of toxoplasmosis in these patients must be done in the first three months, because several studies have reported that the most infections occurred within the first three months after transplantation, which is the period of maximum immunosuppression (15).

The diagnosis of toxoplasmosis can be done by a variety of methods. The difficulty lies in determining whether should consider it as vital step.

Copyright (C) 2013,Ahvaz JundishapurUniversity of Medical Sciences; Published by Kowsar Corp. This is an open-access article distributed under the terms of the Creative Commons Attribution License, which permits unrestricted use, distribution, and reproduction in any medium, provided the original work is properly cited. 
the infection is acute or chronic. Acute infection can best be verified by isolating T. gondii or T. gondii DNA from the patient's blood or finding tachyzoites in tissue or bodily fluids. In Ahvaz, capital of Khuzestan province, Southwest of Iran, the evaluation of toxoplasmosis in renal transplant recipient had not been investigated, and it was the first serology and molecular survey conducted in this point of the country.

\section{Objectives}

The current study aimed to compare the outbreak of toxoplasmosis in renal transplant recipients with those of the control group and also to evaluate the possible dissemination of this infection in the patients.

\section{Materials and Methods}

\subsection{Sample Collection}

In this cross-sectional study a total of 100 renal transplant recipients who referred to hospitals of Ahvaz Jundishapur University of Medical Sciences, were selected as an experimental group, and 100 healthy people were selected as a control group. At first each of them filled out a questionnaire including demographic data, such as gender, age and any contacts with cat and domestic animals, consumption of under-cooked meat, educational level of the population and etc. Approximately $10 \mathrm{~mL}$ of venous blood was drawn at the same time and divided in two parts, first for testing the presence of Toxoplasmaspecific IgG and IgM antibodies and the second for PCR technique. Serum samples were stored at $-20^{\circ} \mathrm{C}$ until the ELISA diagnosis test was applied.

\subsection{Serology Methods}

The specific IgG and IgM antibodies of $T$. gondii in the two groups were detected by ELISA technique (Torch-IgG, IgM-Trinity Biotech Company). According to the manufacturer's protocol, the IgG and IgM levels lower than 1.1 $\mathrm{UI} / \mathrm{mL}$ were reported as a negative and levels equal or higher than $1.1 \mathrm{UI} / \mathrm{mL}$ were reported as a positive.

\subsection{DNA Extraction}

DNA from blood samples was obtained by using Genomic DNA blood and tissue kit (Qiagen, Hilden, Germany) according to the manufacturer's instructions (Bioneer, USA). At first each blood sample was mixed with an equal volume of sterile $2 \%$ Dextran T 500 (Pharmacia) and regimented for 15 minutes. The leucocyte-rich supernatant was collected in $2 \mathrm{ml}$ tubes and centrifuged at $2000 \mathrm{x} \mathrm{g}$ for 10 minutes. The pellet was kept at $-80^{\circ} \mathrm{C}$ for PCR (19).

\subsection{PCR Amplification}

PCR was done to amplify the coding region of the GRA6 gene. Target of the GRA6 gene was amplified with specific primers, forward primer, 5'-GTAGCGTGCTTGTTGGCGAC-3' and reverse primer, 5'-ACAAGACATAGAGTGCCCC-3' (20). Amplification was carried out with $10 \mathrm{pmol}$ of each primer and $10 \mu \mathrm{l}$ of extracted DNA in $20 \mathrm{ml}$ of modified Taq DNA polymerase Master Mix RED reaction (Bioneer Korea) containing $75 \mathrm{mM}$ Tris- $\mathrm{HCl}$ (PH 8.5), $20 \mathrm{mM}$ (NH4)2SO4, 1.5 mM MgCl2, 0.1\% Tween 20, 0.2 mM dNTPs, $0.025 \mathrm{U} / \mu \mathrm{L}$ Amplicon Taq DNA polymerase, inert red dye and a stabilizer. The PCR conditions were 5 minutes at $95^{\circ} \mathrm{C}$ followed by 35 cycles of 30 seconds at $94^{\circ} \mathrm{C}, 1$ minute at $60^{\circ} \mathrm{C}, 2$ minutes at $72^{\circ} \mathrm{C}$, and a final elongation of $72^{\circ} \mathrm{C}$ for 7 minutes (20). The PCR products were detected in $1.5 \%$ ethidium-bromide-stained agarose gels.

\subsection{Statistical Analysis}

Data were analyzed by using SPSS (version 15) software. Significance of difference was analyzed by chi-squared test.

\section{Results}

Totally 34 cases (34\%) of the renal transplant recipients and 26 cases (26\%) of the control were positive for antiToxoplasma IgG. In addition, 18 from renal transplant recipients (18\%) and 4 from control (4\%) were positive for anti-Toxoplasma IgM. In the current study there was no significant association between consumption of undercooked meat and close contact with domestic animals with seropositivity of toxoplasmosis $(\mathrm{P}>0.05)$. The difference between female and male, urban and rural subjects was not statistically significant $(P>0.05)$. There was no significant difference between consumption of pipeline water source and unfiltered water in prevalence of Toxoplasmosis $(\mathrm{P}>0.05)$. The influence of educational level on seropositivity rate of Toxoplasma antibody was not observed. The frequency of serum anti-Toxoplasma IgG and IgM in renal transplant recipients and members of the control group according to age and sex are shown in Tables 1 and 2.

Table 1. Distribution of Toxoplasma Seroprevalence by ELISA Test According to Age in Renal Transplant Recipients and Control Groups

\begin{tabular}{lllll}
\hline \multirow{2}{*}{ Age, $\mathbf{y}$} & \multicolumn{4}{c}{ Antibodies, No. (\%) } \\
\cline { 2 - 5 } & RTRG $^{\mathrm{a}}\left(\mathbf{I g M}^{+}\right)$ & $\mathbf{C G}^{\mathrm{a}}\left(\mathbf{I g M}^{+}\right)$ & $\mathbf{R T R G}\left(\mathbf{I g G}^{+}\right)$ & $\mathbf{C G}\left(\mathbf{I g G}^{+}\right)$ \\
\hline $\mathbf{1 6 - 2 0}$ & $2 / 22(9.09)$ & $0 / 15(0)$ & $5 / 22(22.7)$ & $5 / 15(33)$ \\
$\mathbf{2 1 - 4 0}$ & $11 / 59(18.6)$ & $4 / 84(4.7)$ & $23 / 59(38.9)$ & $21 / 84(25)$ \\
41- 60 & $5 / 19(26.3)$ & $0 / 1(0)$ & $6 / 19(31.5)$ & $0 / 1(0)$ \\
61-80 & $0 / 0(0)$ & $0 / 0(0)$ & $0 / 0(0)$ & $0 / 0(0)$ \\
Total & $18 / 100(18)$ & $4 / 100(4)$ & $34 / 100(34)$ & $26 / 100(26)$ \\
\hline a Abbreviations: RTRG, Renal Transplant Recipients Group; CG, Control \\
Group
\end{tabular}


Table 2. Distribution of Toxoplasma Seroprevalence by ELISA Test According to Sex in Renal Transplant Recipients and Control Group

\begin{tabular}{lllll}
\hline \multirow{2}{*}{ Gender } & \multicolumn{4}{c}{ Antibodies, No. (\%) } \\
\cline { 2 - 5 } & $\mathbf{R T R G}^{\mathrm{a}}\left(\mathbf{I g M}^{+}\right)$ & $\mathbf{C G}^{\mathrm{a}}\left(\mathbf{I g M}^{+}\right)$ & $\mathbf{R T R G}\left(\mathbf{I g G}^{+}\right)$ & $\mathbf{C G}\left(\mathbf{I g G}^{+}\right)$ \\
\hline Male & $11 / 64(17.1)$ & $3 / 59(5)$ & $22 / 64(34.3)$ & $8 / 59(13.5)$ \\
Female & $7 / 36(19.4)$ & $1 / 41(2.4)$ & $12 / 36(33.3)$ & $18 / 41(43.9)$ \\
Total & $18 / 100(18)$ & $4 / 100(4)$ & $34 / 100(34)$ & $26 / 100(26)$ \\
\hline $\begin{array}{l}\text { a Abbreviations: RTRG, Renal Transplant Recipients Group; CG, Control } \\
\text { Group }\end{array}$
\end{tabular}

PCR had positive results with two of the 100 blood samples from renal transplant recipients group but there were no positive results with those of the control group samples. The size of the PCR products was around 800 base pair (bp) (20) (Figure 1).

Figure 1. PCR Amplification Products of T. gondii GRA6, in Blood Samples of Renal Transplant Recipients

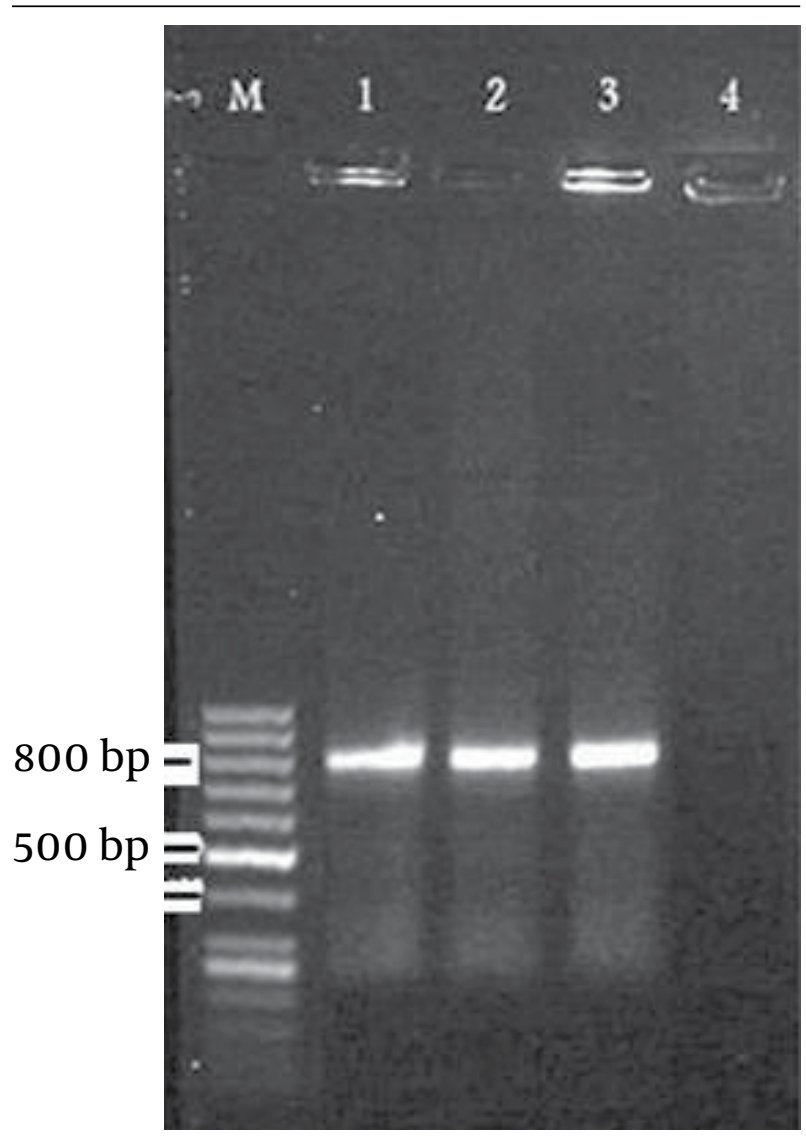

M, molecular weight marker; 1, positive control (Toxoplasma tachyzoites); 2 and 3, positive blood samples; 4 , negative control (H2Odest instead of DNA)

\section{Discussion}

Over half of the world's human population is estimated to carry a Toxoplasma infection (21). Transmission to humans usually takes place by eating raw meat containing tissue cysts or eating infectious oocysts via food or water contaminated with feline faeces. It is rare but potentially life-threatening in patients with immune-depression, such as transplant patients (22). In these patients, transmission of T. gondii from a seropositive donor to a seronegative recipient is a significant potential cause of the disease $(20,21)$. Toxoplasmosis in renal transplantation can cause mortality in up to $65 \%$ of recipients (15). In Iran, renal transplant donors and recipients are not screened for toxoplasmosis since T. gondii infections in renal transplant recipients are thought to be rare.

In many studies, contaminated drinking water, close contact with cats as domestic pets and eating uncooked meat have been implicated as sources of Toxoplasma infection in humans worldwide (23-27), but there was no statistically significant association between these risk factors and Toxoplasma seropostivity in the current study. In this study specific IgG and IgM antibodies of $T$. gondii in the experimental and control groups were detected by ELISA technique. This method is the most common approach used to identify toxoplasmosis and can be used to diagnose a primary infection (28).

In addition, PCR was used to detect $T$. gondii parasite in blood samples, because serological methods are usually not useful to distinguish recent from past infections and T. gondii-specific IgM remains detectable and may remain detectable for more than 1 year after primary infection (29). Especially in immunodeficient patients antibody titers are much more difficult to interpret and in the case of reactivation, the value of serology is limited. PCR method is a sensitive and specific tool to detect T. gondii that can prove the presence of Toxoplasma in the samples (30-32). In the current study, the frequencies of the two antibodies (IgM and IgG) in renal transplant recipients were significantly higher than those of the control group, especially for IgM.

Gharavi et al. also reported a significantly higher prevalence of anti-T. gondii IgM and IgG antibodies in renal transplant recipients than those of the control subjects (33). Gharavi et al. detected IgM and IgG anti-Toxoplasma antibodies in renal transplant recipients before and after transplantation by different methods and detected no IgM positive reactions in pre-transplantation samples. However, IgM was detected in post-transplantation samples (34). Nateghirostami et al. also identified the IgG antibody titer against Toxoplasma in renal transplant recipients by IFA technique. In their study the prevalence rate of toxoplasmosis was 7.1\% (35). This result is significantly lower than that of the current finding $(\mathrm{P}<0.05)$. This dif- 
ference may be due to the methods employed, ELISA was used in the current study.

Garedaghi et al. in a cross-sectional survey on a number of 96 blood samples of the kidney recipients and a number of 96 blood samples of control group, tested by ELISA method, showed the prevalence of anti-Toxoplasma IgG in kidney recipients was $36.46 \%$ in comparison with $2.08 \%$ in control. This result is approximately similar to the finding of the current study (36). Nissapatorn et al. in a study in Kuala Lumpur, Malaysia conducted on 247 of renal patients; detected anti-Toxoplasma antibodies in $56.7 \%(140 / 247)$ of the patients. They indicated valuable differences between renal patients and control groups (37). The current study detected the $T$. gondii parasite in 2 of the blood samples. All PCR-positive samples belonged to patients with positive for IgM anti-Toxoplasma antibodies.

Lamoril et al. detected T. gondii in 19 blood samples of patients with AIDS by PCR (19). Aubert et al. detected $T$. gondii in peripheral blood samples, 30 days after renal transplantation by PCR in 1996 (38). PCR techniques are suitable for immune-compromised patients because these methods do not depend on the host immune responses and allow for direct detection of T. gondii DNA from a variety of clinical samples and facilitate the diagnosis and follow-up of the severe infection in patients with immunodeficiency $(39,40)$.

In the current investigation the presence of Toxoplasma parasite was detected successfully in IgM positive patients indicating dissemination of the parasites in this group and no amplification was seen with DNA from blood samples of IgM negative patients and controls. This study revealed higher prevalence of toxoplasmosis in renal transplant recipients compared to healthy people and also indicated dissemination of toxoplasmosis in the patients. Toxoplasmosis in renal transplant recipients is a complication that may cause important morbidity and mortality. Physicians must be aware of this possibility and should apply preventive measures and make an early diagnosis in the case of compatible symptoms. Screening and follow up for toxoplasmosis in this vulnerable group are suggested.

\section{Acknowledgements}

The permission of the current study has been granted by the Ahvaz Jundishapur University of Medical Sciences and approved in the ethical committee (code no. CMRC41).The authors wish to thank all personnel of Ahvaz hospitals for their kind cooperation. The authors declare that they have no conflicts of interest.

\section{Authors' Contribution}

Shahrzad Soltani (ELISA and PCR performance), Shahram Khademvatan (Revising the text), Jasem Saki (All parts of the research) Heshmatollah Shahbazian (Diagno- sis of the patients and contribution in sample collection).

\section{Financial Disclosure}

The authors declare no conflict of interests.

\section{Funding/Support}

Research Deputy, Ahvaz Jundishapur University of Medical Sciences.

\section{References}

1. Montoya JG, Liesenfeld O. Toxoplasmosis. Lancet. 2004;363(9425):1965-76.

2. Gopal K, Tripathy SS, Bersillon JL, Dubey SP. Chlorination byprod ucts, their toxicodynamics and removal from drinking water. $J$ Hazard Mater. 2007;140(1-2):1-6.

3. Dubey JP, Beattie CP. Toxoplasmosis of Animals and Man.Boca Raton: CRC Press; 1988.

4. Galvan-Ramirez ML, Guillen-Vargas C, Saavedra-Duran R, Islos-Rodriguez A. Analysis of Toxoplasma gondii antigens with sera from toxoplasmosis patients. Rev Soc Bras Med Trop. 1998;31(3):271-7.

5. Hazrati Tappeh KH, Gharavi MJ, Makhdoumi K, Rahbar M, Taghizadeh A. Prevalence of Cryptosporidium spp. Infection in Renal Transplant and Hemodialysis Patients. Iranian J Publ Health. 2006;35(3).

6. Mariuz P, Bosler EM, Luft BJ. Toxoplasmosis in individuals with AIDS. Infect Dis Clin North Am. 1994;8(2):365-81.

7. Holliman RE, Johnson JD, Adams S, Pepper JR. Toxoplasmosis and heart transplantation. J Heart Lung Transplant. 1991;10(4):608-10.

8. Renoult E, Chabot F, Aymard B, Hestin D, Delorme N, Biava MF et al. Generalized toxoplasmosis in two renal transplant recipients who received a kidney from the same donor. Rev Infect Dis. 1991;13(1):180-1.

9. Israelski DM, Remington JS. Toxoplasmosis in the non-AIDS immunocompromised host. Curr Clin Top Infect Dis. 1993;13:322-56.

10. Renoult E, Georges E, Biava MF, Hulin C, Frimat L, Hestin D, et al. Toxoplasmosis in kidney transplant recipients: a life-threatening but treatable disease. Transplant Proc. 1997;29(1-2):821-2.

11. Lucan M. [Textbook of Surgical Urologic Techniques].Bucuresti: Infomedica; 2001.

12. Novick AC. Surgery of Renal Transplantation and Complications. Vascular Problems in Urologic Surgery.. Philadelphia WB: Saunders; 1983.

13. Wulf MW, van Crevel R, Portier R, Ter Meulen CG, Melchers WJ, van der Ven A, et al. Toxoplasmosis after renal transplantation: implications of a missed diagnosis. J Clin Microbiol. 2005;43(7):3544-7.

14. Hebraud B, Kamar N, Borde JS, Bessieres MH, Galinier M, Rostaing L. Unusual presentation of primary toxoplasmosis infection in a kidney-transplant patient complicated by an acute left-ventricular failure. NDT Plus. 2008;1(6):429-432.

15. Renoult E, Georges E, Biava MF, Hulin C, Frimat L, Hestin D, et al. Toxoplasmosis in kidney transplant recipients: report of six cases and review. Clin Infect Dis. 1997;24(4):625-34.

16. Luft BJ, Remington JS. Toxoplasmic encephalitis in AIDS. Clin Infect Dis. 1992;15(2):211-22.

17. Weenink JJ, Weenink AG, Geerlings SE, van Gool T, Bemelman FJ Severe cerebral toxoplasma infection cannot be excluded by a normal CT scan. Neth J Med. 2009;67(4):150-2.

18. Petersen E, Borobio MV, Guy E, Liesenfeld O, Meroni V, Naessens A, et al. European multicenter study of the LIAISON automated diagnostic system for determination of Toxoplasma gondii-specific immunoglobulin G (IgG) and IgM and the IgG avidity index. JClin Microbiol. 2005;43(4):1570-4.

19. Lamoril J, Molina JM, de Gouvello A, Garin YJ, Deybach JC, Moda J, et al. Detection by PCR of Toxoplasma gondii in blood in the diagnosis of cerebral toxoplasmosis in patients with AIDS. J Clin Pathol.1996;49(1):89-92. 
20. Fazaeli A, Carter PE, Darde ML, Pennington TH. Molecular typing of Toxoplasma gondii strains by GRA6 gene sequence analysis. Int J Parasitol. 2000;30(5):637-42.

21. Nissapatorn V, Kamarulzaman A, Init I, Tan LH, Rohela M, Norliza A, et al. Seroepidemiology of toxoplasmosis among HIVinfected patients and healthy blood donors. Med J Malaysia. 2002;57(3):304-10.

22. Cervera C, Moreno A. [Infections in recipients of a kidney-pancreas transplant]. Enferm Infecc Microbiol Clin. 2007;25(5):345-55.

23. Sukthana Y, Chintana T, Damrongkitchaiporn S, Lekkla A. Serological study of Toxoplasma gondii in kidney recipients. J Med Assoc Thai. 2001;84(8):1137-41.

24. Wallace MR, Rossetti RJ, Olson PE. Cats and toxoplasmosis risk in HIV-infected adults. JAMA. 1993;269(1):76-7.

25. Magaldi C, Elkis H, Pattoli D, Coscina AL. Epidemic of toxoplasmosis at a university in Sao-Jose-dos Campos, S.P. Brazil. 1. Clinical and serologic data. Rev Latinoam Microbiol Parasitol (Mex). 1969;11(1):5-13.

26. Choi WY, Nam HW, Kwak NH, Huh W, Kim YR, Kang MW, et al. Foodborne outbreaks of human toxoplasmosis. J Infect Dis. 1997;175(5):1280-2.

27. Lin YL, Liao YS, Liao LR, Chen FN, Kuo HM, He S. Seroprevalence and sources of Toxoplasma infection among indigenous and immigrant pregnant women in Taiwan. Parasitol Res. 2008;103(1):67-74.

28. Remington JS, Thulliez P, Montoya JG. Recent developments for diagnosis of toxoplasmosis. J Clin Microbiol. 2004;42(3):941-5.

29. Liesenfeld O, Press C, Montoya JG, Gill R, Isaac-Renton JL, Hedman $\mathrm{K}$, et al. False-positive results in immunoglobulin $\mathrm{M}$ (IgM) toxoplasma antibody tests and importance of confirmatory testing: the Platelia Toxo IgM test. J Clin Microbiol.1997;35(1):174-8.

30. Iqbal J, Nampoory MR, Johnv KV, Khalid N, Al-Mousawi M. Determination of antibodies to Toxoplasma gondii and CMV in renal transplant recipients. Transplant Proc. 2003;35(7):2703-5.

31. Holliman R, Johnson J, Savva D, Cary N, Wreghitt T. Diagnosis of toxoplasma infection in cardiac transplant recipients using the polymerase chain reaction. J Clin Pathol. 1992;45(10):931-2.

32. Chabbert E, Lachaud L, Crobu L, Bastien P. Comparison of two widely used PCR primer systems for detection of toxoplasma in amniotic fluid, blood, and tissues. J Clin Microbiol. 2004;42(4):1719-22.

33. Gharavi MJ. Prevalence and diagnosis of Toxoplasmosis in immunodeficient patients. Abstract book of 2nd National Congress of Parasitic Diseases.. Tehran: Tehran University of Medical Sciences; 1997.

34. Gharavi MJ, Jalali S, Khademvatan S, Heydari S. Detection of IgM and IgG anti-Toxoplasma antibodies in renal transplant recipients using ELFA, ELISA and ISAGA methods: comparison of pre- and post-transplantation status. Ann Trop Med Parasitol. 2011;105(5):367-71.

35. Nateghi Rostami M, Eskandari E, Garoosi Z, Mohajeri N, Rezaian M, Keshavarz H. Serological Study of Toxoplasma gondii Infection Using IFA Method in Renal Transplant Recipients. Iranian J Parasitol. 2006;1(1).

36. Garedaghi Y, Safarmashaei S. Survey of Toxoplasma Contamination in Kidney Recipient Patients by ELISA Method and Comparison it with Control Group in Tabriz (East-azerbaijan), Iran. Adv Environ Biol. 2011;5(4):769-772.

37. Nissapatorn V, Leong TH, Lee R, Init Ithoi, Ibrahim J, Yen TS. Seroepidemiology of toxoplasmosis in renal patients. Southeast Asian J Trop Med Public Health. 2011;42(2):237-47.

38. Aubert D, Foudrinier F, Villena I, Pinon JM, Biava MF, Renoult E. PCR for diagnosis and follow-up of two cases of disseminated toxoplasmosis after kidney grafting. J Clin Microbiol. 1996;34(5):1347.

39. Homan WL, Vercammen M, De Braekeleer J, Verschueren H. Identification of a 200- to 300 -fold repetitive 529 bp DNA fragment in Toxoplasma gondii, and its use for diagnostic and quantitative PCR. Int J Parasitol. 2000;30(1):69-75.

40. Guo ZG, Gross U, Johnson AM. Toxoplasma gondii virulence markers identified by random amplified polymorphic DNA polymerase chain reaction. Parasitol Res. 1997;83(5):458-63. 